American J. of Engineering and Applied Sciences 3 (3): 534-539, 2010

ISSN 1941-7020

(C) 2010 Science Publications

\title{
Potted Plants on Flat Roof as a Strategy to Reduce Indoor Temperature in Malaysian Climate
}

\author{
${ }^{1}$ Asmat Ismail, ${ }^{2}$ Muna Hanim Abdul Samad and ${ }^{2}$ Abdul Malek Abdul Rahman \\ ${ }^{1}$ Department of Building, University Technology MARA, Perak, Malaysia \\ ${ }^{2}$ Architecture Programme, University Sains Malaysia, Pulau Pinang, Malaysia
}

\begin{abstract}
Problem statement: The phenomenon of global warming or climate change has led to many environmental issues including higher atmospheric temperatures, intensive precipitation, increase greenhouse gaseous emission and of course increase indoor discomfort condition. Researchers worldwide collectively agreed that one way of reducing the impact of global warming is by implementing green roof technology which integrates vegetation, growing medium and water proofing membrane on top of the roof surface. However, none of them have ever studied on how much the potted plants on the roof top could contribute to lessen the environmental problems. Therefore, this study investigates the effect of potted plants on flat roof on the indoor temperature inside building in Malaysian climate. Approach: This study emphasized on experimental approach of the room with flat roof. Measurements were conducted in two phases i.e., room with potted plant on the roof and room with bare roof. The measurements were conducted on the same room. Results: The experiment showed a promising result whereby the average indoor temperature dropped between 0.21 and $1.73^{\circ} \mathrm{C}$ had been observed during the measurements, while average indoor surface temperatures difference between roof with potted plants and bare roof of $7.86^{\circ} \mathrm{C}$ had been recorded during daytime hour. Conclusion: Potted plants on flat roof had a great potential in reducing the indoor temperature of the room underneath and could contributed to the reduction of energy consumption in building.
\end{abstract}

Key words: Global warming, potted plants, indoor temperature, carbon dioxide

\section{INTRODUCTION}

Climate change which manifested in global warming has become critical worldwide. High temperature, abundant precipitation and rise of sea level are the indicators of global warming. Since the late 19th century, the mean global temperature has increased by about $0.3-0.6^{\circ} \mathrm{C}$ (Maslin, 2004). Global warming results from the increase of greenhouse gas emissions. Carbon dioxide $\left(\mathrm{CO}_{2}\right)$ which is the leading greenhouse gas is said to be the reason for this global warming. According to Smith (2005), climatologist worldwide agreed that carbon dioxide increase in atmospheric concentration was because of human activities. As the $\mathrm{CO}_{2}$ in atmosphere increases, the ability of earth surface to reradiate heat to the atmosphere is lessen. $\mathrm{CO}_{2}$ acts like a blanket over the surface and keep the earth warmer than it would otherwise be (Houghton, 2004).

The warmer climate outside will also affect the indoor temperature of building. When the outdoor air temperature increases, building will experience indoor discomfort. The demand for mechanical ventilation will be critical and lead to higher energy consumption in building. Recent research discovered that the ability of ocean to absorb $\mathrm{CO}_{2}$ in atmosphere decrease because of global warming. So, the $\mathrm{CO}_{2}$ concentration in atmosphere is predicted to be continuously increased. Naturally plants play a very important role in absorbing $\mathrm{CO}_{2}$ from the atmosphere in order to counter the detriment of the greenhouse effect. Urbanization process which associated with the deterioration of green areas has created an unhealthy environment and become a major contributor to climate change. Environmental pollution is becoming common in urban area and produced many environmental impacts to the society. One of the effect is an urban heat island phenomenon which is the temperature in urban areas is high than the surrounding area.

One way of reducing the impact of global warming is by implementing green roof technology which is roof that consists of vegetation and growing medium and sometime refers to roof garden in some places (Anon, 2007; Dunnett and Kingsbury, 2004). Many researchers have proved that green roof could give many environmental benefits to the buildings and occupants.

Corresponding Author: Asmat Ismail, Department of Building, University Technology MARA, Perak, Malaysia 
Eomorfopoulou and Aravantinos (1998) found that by providing large surfaces with vegetation, they contribute to the improvement of thermal performance of building. This finding was supported by Niachou $\mathrm{et} \mathrm{al}$. (2001) which discovered the indoor temperature values in the building with green roof are lower during the day. They measured the roof temperatures in noninsulated building with and without green roof. The result shows that the surface temperature of noninsulated building without green roof are vary from 42 $48^{\circ} \mathrm{C}$ while the surface temperatures of the green roof upon non-insulated building are lower and ranging from $28-40^{\circ} \mathrm{C}$. They also concluded that the existence of large temperature differences due to the installation of green roof could contribute to energy saving potential. A well designed and managed green roof could behave as a high quality insulation device and reducing the heat flux through the roof in summer (Barrio, 1998). A group of researchers form Japan has conducted the field measurements of roof lawn garden planted on nonwoven fabric on an actual three-storey pre-cast reinforced concrete building. From the measurements, it confirmed that the amount of heat coming into room during summer was reduced by a roof lawn garden. The reduction of roof slab surface temperature from 60$30^{\circ} \mathrm{C}$ was observed during the measurement and estimation of $50 \%$ in heat flux was calculated by simple calculation (Onmura et al., 2001). Another study on the thermal performance of extensive rooftop greenery systems has been conducted in Singapore by Nyuk Hien et al. (2007). That study concluded that the green roof tends to experience lower surface temperature than the original exposed roof surface. In areas well covered by vegetation, over $60 \%$ of heat gain was prevented by the implementation of green roof system. According to that study, the heat flux through the roof structure was greatly reduced after the installation of the green roof system. Those findings strongly supported the above statement. The Pen State Center for Green Roof Research has developed a green roof field experiment in Central Pennsylvania which consists of 6 separate experimental buildings. Three buildings were developed with green roofs and the other three were constructed with dark roofs. The temperature, meteorological conditions and water retention and runoff were monitored on those roofs. The hourly averages of temperature data was taken every 5 min. These data demonstrate the cooling potential of green roof surfaces compared to dark impervious roof surface. The peak temperature of $30^{\circ} \mathrm{C}$ or lower can be measured on the green rooftops (Gaffin et al., 2005). Other researchers from India discovered that the combination of green roof and solar thermal shading lead to the reduction of average indoor air temperature by $5.1^{\circ} \mathrm{C}$, from the average indoor air temperature for the bare roof (Kumar and Kaushik, 2005).

Researchers from Columbia University Center for Climate Systems Research and NASA Goddard Institute for space studies had discovered that green roof could potentially reduce energy usage, fossil fuel consumption and greenhouse gas emissions. On average $2{ }^{\circ} \mathrm{C}$ reduction in indoor air temperatures were measured in building with green roofs during daytime hours and $0.3^{\circ} \mathrm{C}$ higher at night. That study also confirmed that vegetated surface, green roofs may reduce outdoor air temperature and urban heat island effect through evapotranspiration, shading and increased albedo. Thus it also supported the above mention findings. That study also discovered that a $50 \%$ extensive green roof scenario reduced New York City's average surface temperature by $<0.1-0.8^{\circ} \mathrm{C}$ and the green roofs could help the region prepare to adapt the global warming by reducing energy usage, fossil fuel consumption and greenhouse gas emissions by moderating temperature inside the building. The need for space heating and cooling is reduced by cooling the surface because green roof reduces the flow of energy into and out of a building (Rosenzweig et al., 2006).

Spala et al. (2008) found that the installation of green roof on the office building in Athens presents a significant contribution to the energy saving during summer period. The remarkable reduction of building cooling load was estimated during the simulation study. However, during winter, the effect of green roof installation is not significant because of the variation of heating load was quite small. Green roof also can effectively reduce the need of air conditioning in summertime thus contribute to energy saving in building (Liu and Baskaran, 2003). Liu (2006), in another study, made a conclusion that green roofs are giving better performance in the summer than in the winter because the ability of reducing heat gain than heat loss. Researchers also proved that plants and substrates are the major contributor to the thermal performance and energy reduction aspect. Several study related to those variables are explain below.

Most previous studies have focused on green roof or planted roof which is the roof that consists of vegetation planted over a growing medium and water proofing membrane. No one has even published the result of using potted plants on roof top to reduce the indoor temperature of the room underneath. Therefore this study is focuses on how potted plants on flat roof could contribute to the thermal reduction of building indoor environment. The objective of this study is to 
investigate the effect of potted plants on flat roof to the indoor temperature reduction inside building in Malaysian climate condition.

\section{MATERIALS AND METHODS}

The study was conducted on a flat roof of a single storey detached house in University Sains Malaysia, Penang. This single storey detached house constructed with brickwork and exposed to full sunlight during the day. Figure 1 shows the bedroom room constructed with concrete flat roof, located at the back of the house, which has been selected to be the tested room for this study. This room oriented to east-west orientation and seems to experience higher temperature during daytime hours because of full sun exposure. The room measuring $3.05 \times 2.73 \times 3.05 \mathrm{~m}$ consists of a door and a window on one side of the brick wall. The flat roof surface was insulated with bituminous felt which is black in color. The indoor air temperatures, indoor surface temperatures and outdoor surface temperatures were measured to evaluate the thermal performance of room with and without potted plants on the roof.
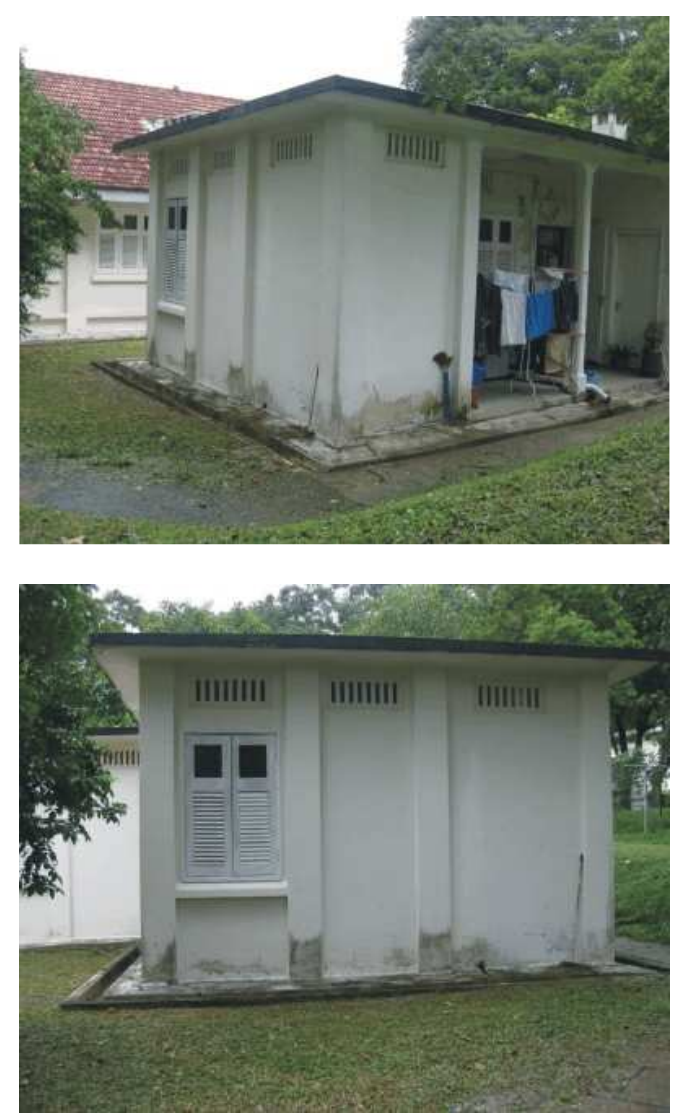

Fig. 1: Tested room located at the back of the house
In this study, two types of measurement were conducted on the tested room. The first measurement was the room with potted plants on top of the roof and the second one was the measurement of the same room with bare roof. Since the room was located at the back of the house which attached to another room and kitchen and only roof on top of the tested room is going to be measured, the rest of flat roof was covered by plywood to avoid transferring of heat to the tested roof surface.

Plant selection: Ipomoea pes capre or beach morning glory has been choosing as sample to be placed on the flat roof. This plant was selected due to its capability of uptaking higher carbon dioxide compare to other plants and also it is durable to higher outdoor temperature. Determination of plant to be selected as sample was done at Marine Research Station, Muka Head, Teluk Bahang, Pulau Pinang on 1 July 2008. $\mathrm{CO}_{2}$ uptakes of 5 different types of potted plant were measured on that day which is syngonium podophyllum (arrowhead plants), ipomoea batatas (sweet potato), jasminum sambac, ipomoea horsfalliae (cardinal creeper), ipomoea pes-caprae (beach morning glory).

The measurement: The measurements were conducted on the different days starting on 8 June 2009 until 20 June 2009. Each type of measurement was conducted within one week time. The first week was the measurement of room with potted plants on the roof top and the measurement of the room with bare roof was conducted on the following week. About 102 pots of ipomoea pes capre were placed on the roof to cover the roof top. Data acquisition system was installed in the room. The outdoor air temperature, solar radiation, outdoor surface temperature of roof, indoor air temperature, indoor surface temperature, indoor humidity and indoor wind speed were monitored during the experiment.

Figure 2 shows the sensors which have been placed on top of the roof and in the testing room underneath. Three sensors were placed on top of the roof i.e., LI200SA pyranometer to measure global radiation, 1906 NRG 110S temperature sensor with radiation shield to measure ambient air temperature and surface temperature sensor to measure the surface temperature on the testing room. Another four sensors were placed inside the testing room i.e., indoor air temperature sensor, indoor air velocity sensor, indoor surface temperature sensor and indoor relative humidity sensor. Pyronometer was set at $340 \mathrm{~mm}$ from the roof surface while outdoor temperature sensor was set at $350 \mathrm{~mm}$ from the roof surface. Indoor air temperature 
and indoor air humidity sensors were placed at $2.58 \mathrm{~m}$ from the floor while indoor wind speed sensor was placed at $2.49 \mathrm{~m}$ from the floor. The data were logged every 15 min using data acquisition system.

Figure 3 shows the roof filled with potted plants and bare roof which has been installed with surface temperature sensor. During the measurements, data were logged using data acquisition system ADAM4000 as shows in Fig. 4.

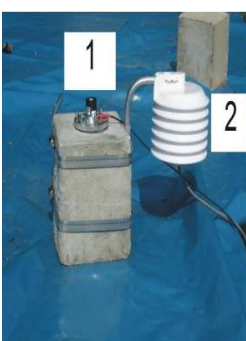

(a)

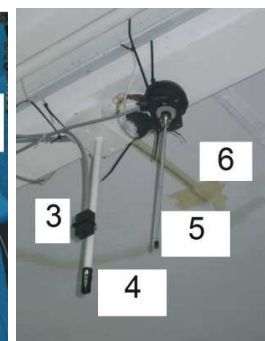

(b)
Fig. 2: (a) 1-pyronometer, 2-Ambient air temperature sensor; (b) 3-indoor humidity sensor, 4-indoor windspeed sensor, 5-indoor air temperature sensor and 6-surface temperature sensor

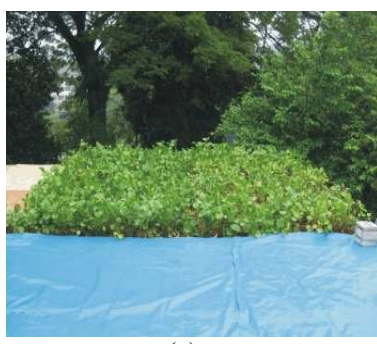

(a)

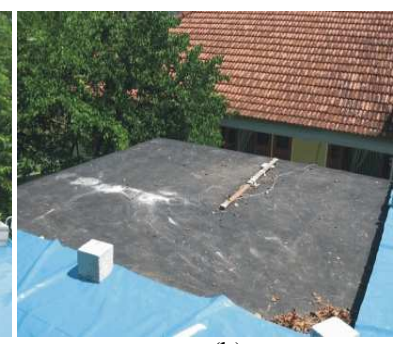

(b)
Fig. 3: (a) Roof filled with potted plants (ipomoea pes capre); (b) Bare roof with outdoor surface temperature sensor placed on it surface

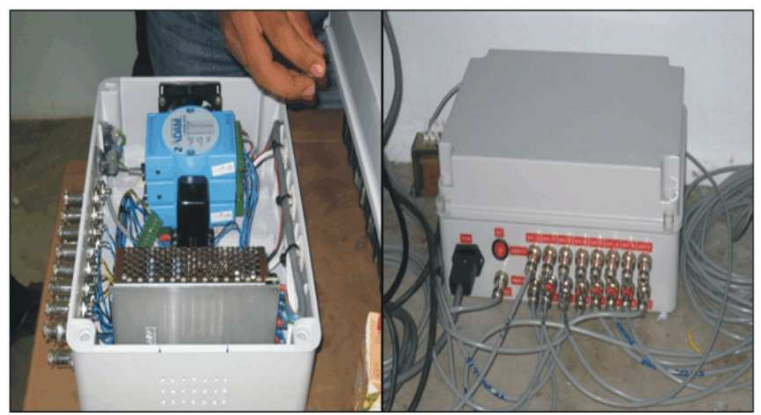

Fig. 4: Data acquisition system using ADAM (analogue to digital converter) was used to $\log$ the data during measurements

\section{RESULTS AND DISCUSSION}

Since data collection for both type of roofs were obtained from different day of measurements, the average readings of 6 days for every type of roof were analyzed. The measurements for roof with potted plants were conducted from 8 June 2009 until 13 June 2009 while measurements for bare roof have been conducted from 15 June 2009 until 20 June 2009.

Figure 5 shows the average outdoor temperatures between bare roof and roof potted plants which was quite similar to each other. The average temperature difference between 0.02 and $1.91^{\circ} \mathrm{C}$ was observed from the data.

Figure 6 shows that the average temperatures for 6 days range from $28.58-29.93^{\circ} \mathrm{C}$ were observed from roof with potted plants while temperatures range from $28.88-31.58^{\circ} \mathrm{C}$ was observed from the bare roof.

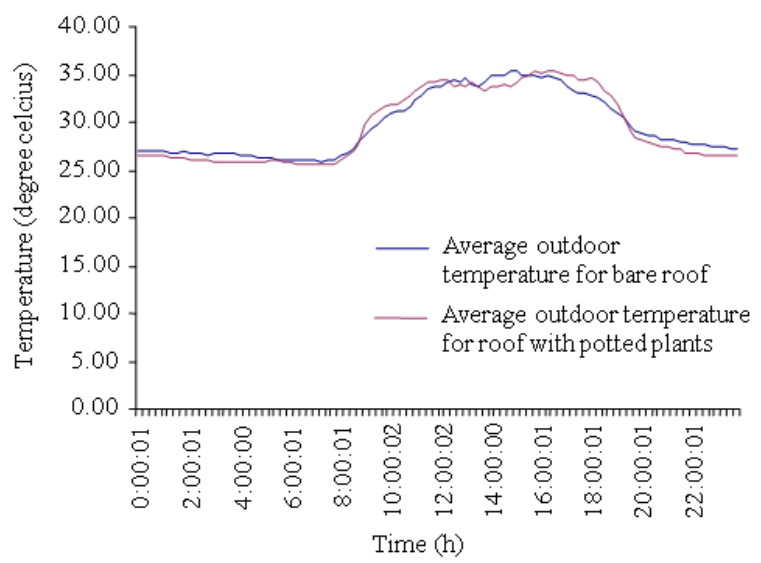

Fig. 5: Comparison of average outdoor temperature between roof with potted plants and bare roof for 6 days reading

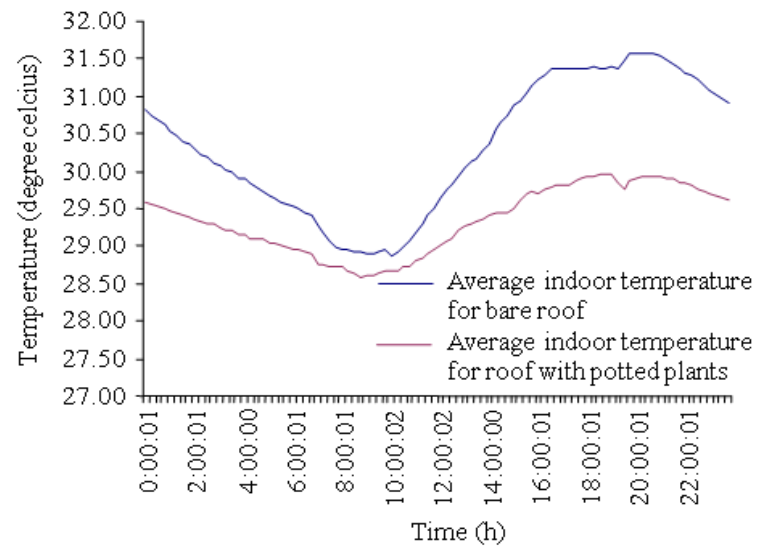

Fig. 6: Comparison of average indoor air temperature between bare roof and roof with potted plants for 6 days reading 
Am. J. Engg. \& Applied Sci., 3 (3): 534-539, 2010

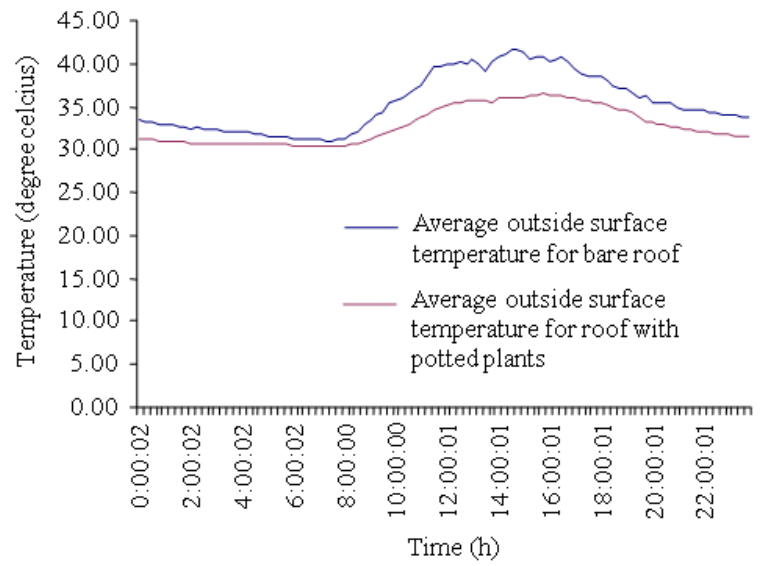

Fig. 7: Comparison of average outdoor surface temperature between roof with potted plants and bare roof for 6 days reading

The minimum and maximum temperature differences of 0.21 and $1.73^{\circ} \mathrm{C}$ were observed during the experiment at $10.00 \mathrm{O}^{\prime}$ 'clock in the morning and 7.30 o'clock in the evening. Average temperature difference between those two types of roof was recorder at $1.20^{\circ} \mathrm{C}$ from $10 \mathrm{O}^{\prime}$ clock in the morning until 12 midnight. The average indoor temperature for both roof started to increase from $10 \mathrm{am}$ in the morning until 9 O'clock in the evening and after that gradually fall down. This is due to the roof started to absorb heat during daytime hours and slowly released the heat stored during night time.

Figure 7 shows that maximum temperature differences between average outdoor surface temperatures of roof with potted plants and bare roof as high as $5.74^{\circ} \mathrm{C}$ at $4.45 \mathrm{pm}$ and the minimum value was $0.62^{\circ} \mathrm{C}$ at $7.15 \mathrm{am}$. From the result, potted plants can significantly reduce the surface temperature and the air temperature of room underneath.

From Fig. 8, we can see that there was a bit different in average solar radiation intensity for both roofs. However, even though solar radiation turned to be higher for roof with potted plants most of the time except between 1.00-3.00 pm, the indoor air temperature underneath that green roof still lower than indoor air temperature for the room with bare roof. It shows that potted plants have an ability to lower the indoor air temperature and significantly could increase indoor comfort condition.

Figure 9 shows that the maximum average indoor surface temperature difference between both roofs was $7.86^{\circ} \mathrm{C}$ at $4.45 \mathrm{pm}$ and minimum value was $0.63^{\circ} \mathrm{C}$ at $8.30 \mathrm{am}$. This result shows that average indoor surface temperature reduction is markedly high due to the installation of potted plants on the rooftop.

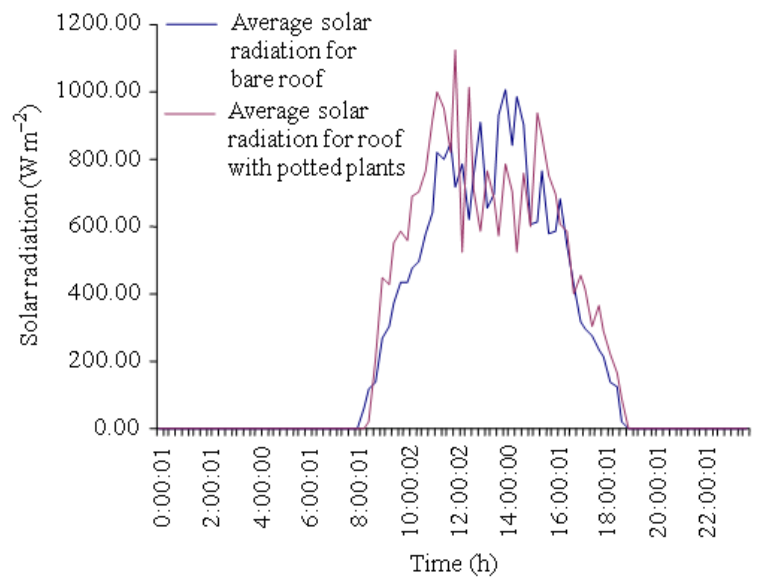

Fig. 8: Comparison of average solar radiation between roof with potted plants and bare roof for 6 days reading

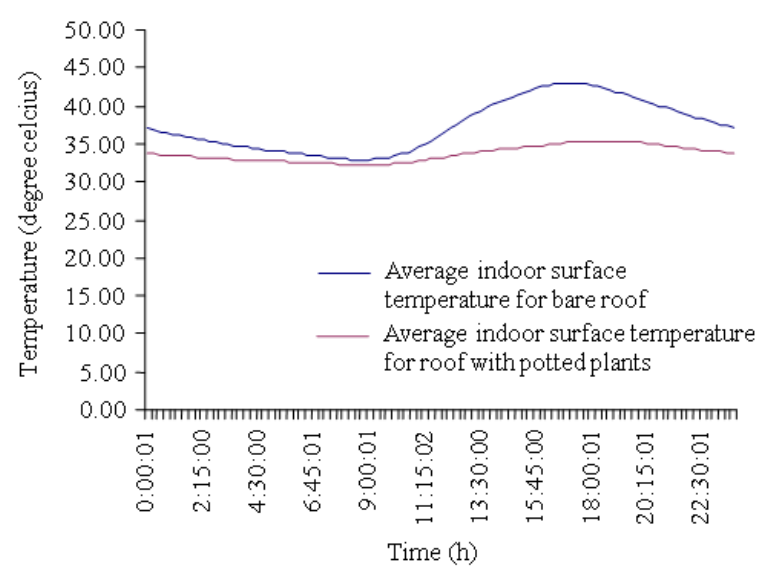

Fig. 9: Comparison of average indoor surface temperature between roof with potted plants and bare roof for 6 days reading

\section{CONCLUSION}

The results obtained from the experiment confirmed that by putting the potted plants on top of the roof, the indoor air temperature of the room underneath significantly reduced. Surface temperatures of roof with potted plants also give a significant reduction which contributed to the reduction of indoor surface temperatures and indoor air temperatures. Therefore, instead of using green roof system which consists of multiple layers and complex installation, potted plants also can be applied on roof top to lessen the impact of global warming. They are also easy to install and portable. And the most important thing that they can 
still reduces the indoor air temperatures and also lessens the carbon dioxide concentration in atmosphere.

\section{REFERENCES}

Anon, 2007. Introduction to green roofs, eco-roofs of roof gardens.

http://www.livingroofs.org/livingpages/greenroofin tro.html

Barrio, E.P.D., 1998. Analysis of the green roofs cooling potential in buildings. Energy Build., 27: 179-193. DOI: 10.1016/S0378-7788(97)00029-7

Dunnett, N. and N. Kingsbury, 2004. Planting Green Roofs and Living Walls. Timber Press, Portland, ISBN: 0-88192-640-X, pp: 254.

Eomorfopoulou, E. and D. Aravantinos, 1998. The Contribution of a Planted Roof to the Thermal Protection of Buildings in Greece. Energy Build., 27: 29-36. DOI: 10.1016/S0378-7788(97)00023-6

Gaffin, S., C. Rosenzweig, L. Parshall, D. Beattie and R. Berghage et al., 2005. Energy balance modeling applied to a comparison of white and green roof cooling efficiency. Proceeding of 3rd North American Green Roof Conference: Greening Rooftops for Sustainable Communities, May 2005, pp: 4-6.

http://www.roofmeadow.com/technical/.../Gaffinet alPaperDC-0009.pdf

Houghton, J., 2004. Global Warming: The Complete Briefing. 3rd Edn., Cambridge University Press, Cambridge, ISBN: 0-521-81762-5, pp: 351.

Kumar, R. and S.C. Kaushik, 2005. Performance evaluation of green roof and shading for thermal protection of buildings. Build. Environ., 40: 1505-1511. DOI: 10.1016/J.BUILDENV.2004.11.015

Liu, K., 2006. Thermal performance of green roofs in Canada.

http:www.shef.ac.uk/landscape/greenroof/pdf/kare nliu.pdf

Liu, K. and B. Baskaran, 2003. Thermal performance of green roofs through field evaluation. Proceeding of the 1st North American Green Roofs Infrastructure Conference on Greening Rooftops for Sustainable Communities, May 2003, Awards and Trade Show, Chicago, IL., pp: 29-30.
Maslin, M., 2004. Global Warming: A Very Short Introduction. Oxford University Press, New York, ISBN: 0-19-284097-5, pp: 184.

Niachou, A., K. Papakonstantinou, M. Santamouris, A. Tsangrassoulis and G. Mihalakakou, 2001. Analysis of the green roof thermal properties and investigation of its energy performance. Energy Build., 33: 719-729. DOI: 10.1016/S03787788(01)00062-7

Nyuk Hien, W., T.P. Yok and C. Yu, 2007. Study of thermal performance of extensive rooftop greenery systems in the tropical climate. Build. Environ., 42: 25-54. DOI: 10.1016/J.buildenv.2005.07.030

Onmura, S., M. Matsumoto, S. Hokoi, 2001. Study on evaporative cooling effect of roof lawn gardens. Energy Build., 33: 653-666. DOI: 10.1016/S03787788(00)00134-1

Rosenzweig, C., S. Gaffin and L. Parshall, 2006. Green roofs in the New York metropolitan region: Research report. Columbia University Center for Climate Systems Research and NASA Goddard Institute for Space Studies, New York, pp: 59. http://www.ccsr.columbia.edu/cig/greenroofs/Gree n_Roof_Full_Report.pdf

Smith, P.F., 2005. Architecture in a Climate of Change: A Guide to Sustainable Design. 2nd Edn., Architectural Press, Oxford, ISBN: 0750665440, pp: 278.

Spala, A., H.S. Bagiorgas, M.N. Assimakopoulos, J. Kalavrouziotis and D. Matthopoulos et al., 2008. On the green roof system. selection, state of the art and energy potential investigation of a system installed in an office building in Athens. Greece. Renew. Energy, 33: 173-177. DOI: 10.1016/J.renene.2007.03.022 